\title{
Retraction Note: Surface irrigation based on image object detection and fuzzy pid control
}

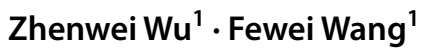 \\ Published online: 16 December 2021 \\ (c) Saudi Society for Geosciences 2021
}

Retraction Note: Arabian Journal of Geosciences (2021) 14: 1807 https://doi.org/10.1007/s12517-021-08119-7

The Editor-in-Chief and the Publisher have retracted this article because the content of this article is nonsensical. The peer review process was not carried out in accordance with the Publisher's peer review policy. The authors have not responded to correspondence regarding this retraction.

The original article can be found online at https://doi.org/10.1007/ s12517-021-08119-7.

Zhenwei Wu

wuzhenwei1656633@163.com

1 College of Advanced Manufacturing Engineering,

Chongqing University of Posts and Telecommunications,

Chongqing 400065, China 